\title{
Preclinical studies for the combination of paclitaxel and curcumin in cancer therapy (Review)
}

\author{
YUMENG WEI $^{1}, \mathrm{XINLIN} \mathrm{PU}^{2}$ and LING ZHAO $^{1}$ \\ ${ }^{1}$ Department of Pharmaceutics, School of Pharmacy, Southwest Medical University; \\ ${ }^{2}$ The Affiliated Hospital of Southwest Medical University, Luzhou, Sichuan 646099, P.R. China
}

Received October 19, 2016; Accepted April 10, 2017

DOI: $10.3892 /$ or.2017.5593

\begin{abstract}
Cancer is one of the most common causes of death and remains the first in China and the second in the US. The common treatments for cancer include surgery, radiation, chemotherapy, targeted therapy and immunotherapy, while chemotherapy remains one of the most important treatments. However, the efficacy of chemotherapy is limited due to drug induced-toxicities and resistance, particularly multiple drug resistance (MDR). Therefore, discovery and development of novel therapeutic drugs and/or combination therapy are urgently needed to reduce toxicity and improve efficacy. Paclitaxel has been widely used to treat various cancers including cervical, breast, ovarian, brain, bladder, prostate, liver and lung cancers. However, its therapeutic efficacy is limited and MDR is a major obstacle. Recently, numerous preclinical studies have shown that the combination of paclitaxel and curcumin may be an ideal strategy to reverse MDR and synergistically improve their therapeutic efficacy in cancer therapy. This review mainly focuses on the current development and progress of the combination of paclitaxel and curcumin in cancer therapy preclinically.
\end{abstract}

\section{Contents}

1. Introduction

2. The combination of paclitaxel and curcumin in cancer therapy

3. Conclusion

\section{Introduction}

As one of the most common causes of death, cancer is a serious health problem globally and the mortality remains the first in

Correspondence to: Professor Ling Zhao, School of Pharmacy, Southwest Medical University, 3-5 Zhongshan Road, Jiangyang, Luzhou, Sichuan 646099, P.R. China

E-mail: zhaoling-998@163.com

Key words: curcumin, paclitaxel, cancer, combination therapy, multiple drug resistance
China and the second in the US (first in 21 states) and other Western countries $(1,2)$. There were 4,292,000 new cases with $2,814,000$ deaths of cancers and the incidence and mortality of lung cancer were the highest in China in 2015 (1). The common treatments for cancer include surgery, radiation, chemotherapy, targeted therapy and immunotherapy, while chemotherapy remains one of the most important treatments $(3,4)$. Numerous chemotherapeutic drugs have been developed and used for the treatment of cancer, such as paclitaxel, cisplatin, 5-fluorouraci, cyclophosphamide, irinotecan, mitomycin $\mathrm{C}$ and doxorubicin (5-11). However, the effectiveness of chemotherapy as monotherapy is limited in cancer therapy due to low water solubility, lack of convincing anticancer activity and therapeutic selectivity, and drug resistance especially multiple drug resistance (MDR) (12-15). Therefore, the combination of various chemotherapeutic drugs with different mechanisms has become the standard clinical practice for cancer treatment (16-24).

Paclitaxel is a natural plant alkaloid that is isolated from the bark of the pacific yew tree and the active ingredient was firstly isolated and named as Taxol by Wani and Wall (25-27). Paclitaxel is a mitotic inhibitor for targeting tubulin by stabilizing the microtubule polymer and protecting it from disassembly to prevent the metaphase spindle configuration of chromosomes. Thus, it caused abnormality of mitotic spindle assembly, chromosome segregation, and cell division, resulting in blocking the progression of mitosis and prolonging activation of the mitotic checkpoint to trigger cell apoptosis or blocking cell cycle arrest at $\mathrm{G} 2 / \mathrm{M}$ without cell division of treated cells (28-33). Although paclitaxel is widely used for the treatment of various cancers including cervical, breast, ovarian, brain, bladder, prostate, liver and lung cancers, the application of paclitaxel in clinic is significantly limited due to MDR (34-39). Many factors may be responsible for the MDR of paclitaxel and the possible mechanisms are proposed in Fig. 1. The multidrug resistance gene 1 encodes the transporter P-glycoprotein (P-gp) leading to MDR (40-46). The activation of protein kinase $B(A k t)$ and nuclear factor- $\kappa \mathrm{B}(\mathrm{NF}-\kappa \mathrm{B})$ is the important cause for $\operatorname{MDR}(47,48)$. The activation of mitogenactivated protein kinases (MAPKs) is also responsible for MDR (49,50). Therefore, in order to improve the therapeutic effect of paclitaxel, it is necessary to reverse its MDR.

Curcumin is an effective monomer component extracted from the roots of Zingiberaceae. It shows many biological 
functions such as antioxidant, anti-inflammation and especially antitumor (51-55). Many previous studies showed that curcumin inhibited cancer cell growth and reversed MDR through various mechanisms including antiproliferation, induction of apoptosis and blocking cell cycle arrest at $\mathrm{G} 2 / \mathrm{M}$ of cancer cells $(56,57)$ as shown in Fig. 2. NF- $\kappa \mathrm{B}$ is a nuclear protein and a transcription factor; it is in activated status in a variety of cancers (58). NF- $\kappa \mathrm{B}$ plays a key role in the aspects of cell proliferation, differentiation, survival, metastasis, and apoptosis. Curcumin inhibits the activation of NF- $\kappa \mathrm{B}$ and $\mathrm{NF}-\kappa \mathrm{B}$ regulated Akt (59-61). Curcumin reduces the expression levels of c-Jun $\mathrm{N}$-terminal kinase (JNK), MAPK p38 and extracellular signal-regulated kinase (ERK) $(62,63)$. Curcumin blocks cell cycle arrest at G2/M of cancer cells (64-67). Curcumin also inhibits the expression of P-gp, therefore, it may not only become a promising anticancer drug but also an excellent agent for MDR reversal (68-71).

Based on the mechanisms of anticancer action of curcumin, it is rational and valuable to use the combination of paclitaxel and curcumin for synergistic anticancer activity and reversing MDR of paclitaxel (Table I). Numerous previous studies showed that the combination of paclitaxel and curcumin reversed the MDR of paclitaxel and inhibited cancer cell growth more effectively than paclitaxel alone. This review focuses on the combination of paclitaxel and curcumin in cancer therapy for different types of cancers.

\section{The combination of paclitaxel and curcumin in cancer therapy}

\section{Cervical cancer}

Anticancer activity. Cervical cancer is the second most common cancer in female reproductive system and almost 500,000 new cases are diagnosed in women worldwide every year (72). It ranked both the fourth-most common cause of cancer and the fourth-most common cause of death from cancer in women worldwide (73). The commonly used chemotherapeutic drugs for the treatment of cervical cancer include cisplatin, paclitaxel, fluorouracil, gemcitabine, ifosfamide and mitomycin C. Recent studies indicated that the combination of paclitaxel and curcumin was quite effective for the treatment of cervical cancer in preclinical settings (74-78). Studies have demonstrated that curcumin sensitized paclitaxel-induced apoptosis via enhancing the expression of p53, activation of caspase-3, -7, -8 and -9 , cleavage of poly(ADP-ribose) polymerase (PARP) and release of cytochrome $\mathrm{c}$ by western blot analysis (74,77). Therefore, the combination of paclitaxel and curcumin may have synergistic anticancer effect and be a promising regimen for the treatment of cervical cancer.

Effect on MDR reversal. MDR significantly affects the antitumor activity of paclitaxel against cervical cancer, while reversal of MDR improves its anticancer effect. A study by Bava et al showed that paclitaxel could activate NF- $\mathrm{BB}$ and Akt leading to the development of MDR of paclitaxel, whereas curcumin was able to reverse MDR of paclitaxel via the inhibition of $\mathrm{NF}-\kappa \mathrm{B}$ (the inhibition of phosphorylation of IKBa and the reduction of $\mathrm{p} 65-\mathrm{NF}-\kappa \mathrm{B}$ subunit) and Akt (74). Cyclooxygenase-2 (COX-2) and cyclin D1 are the most important gene products regulated by $\mathrm{NF}-\kappa \mathrm{B}$ and Akt. Another study by the same group noted that paclitaxel activated the expression

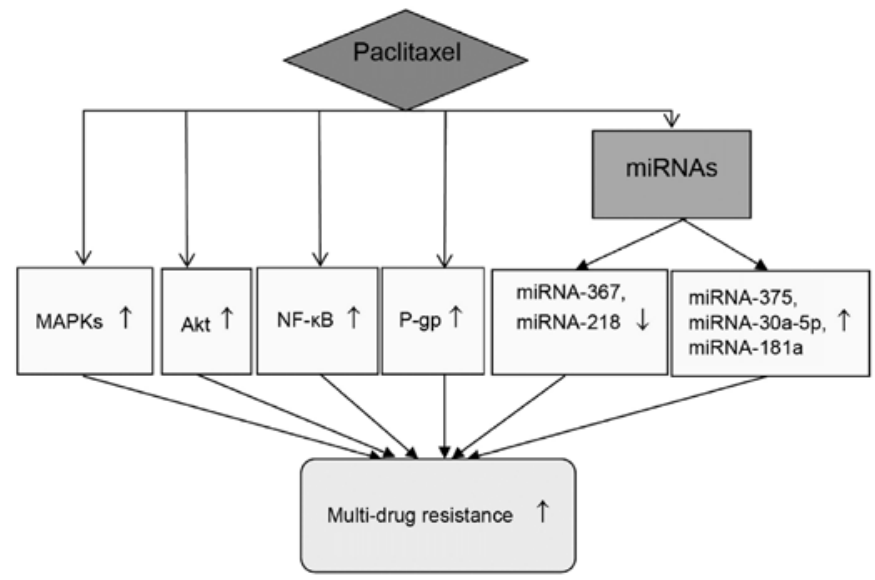

Figure 1. The proposed mechanisms of multiple drug resistance (MDR) of paclitaxel in cancer therapy. $\uparrow$ indicates activation, $\downarrow$ indicates inhibition. MAPKs, mitogen-activated protein kinases; Akt, protein kinase B; NF- $\kappa$ B, nucleas transcription factor $\kappa \mathrm{B}$; P-gp, P-glycoprotein.

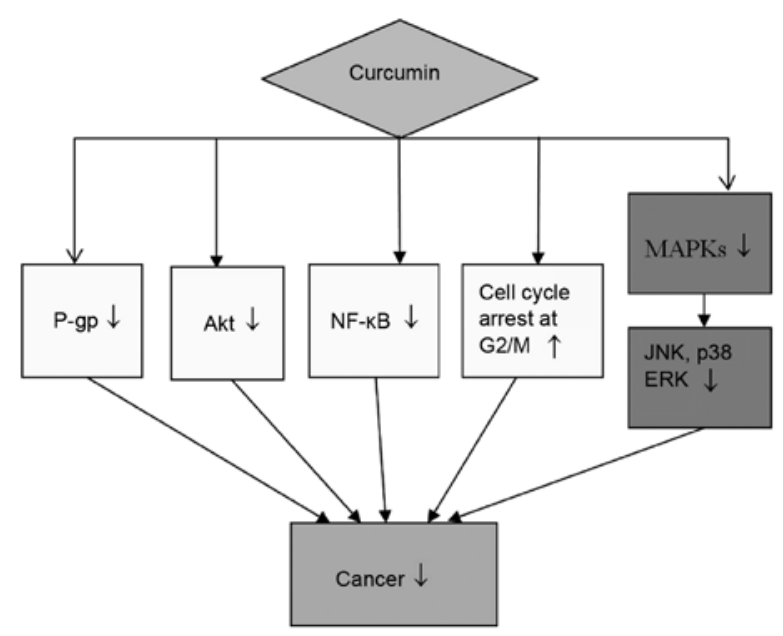

Figure 2. The proposed mechanisms of anticancer activity and multiple drug resistance (MDR) reversal of curcumin in cancer therapy. + indicates activation, - indicates inhibition. P-gp, P-glycoprotein; Akt, protein kinase B; $\mathrm{NF}-\kappa \mathrm{B}$, nucleas transcription factor $\kappa \mathrm{B}$; MAPKs, mitogen-activated protein kinases; JNK, c-Jun n-terminal kinase; ERK, extracellular signal-regulated kinase.

levels of COX-2 and cyclin D1, while curcumin downregulated the expression levels of COX-2 and cyclin D1 (75). The combination of paclitaxel and curcumin could inhibit anti-apoptotic proteins including cellular inhibitor of apoptosis 1 (cIAP1), $\mathrm{X}$-linked inhibitor of apoptosis protein (XIAP) and survivin through the inhibition of $\mathrm{NF}-\kappa \mathrm{B}$ and Akt $(76,77)$. The study also showed that the combination of paclitaxel and curcumin reversed the MDR of paclitaxel by inhibiting JNK, p38 MAPK and ERK (76). Punfa et al reported that the encapsulation of curcumin in polylactic-co-glycolic acid nanoparticles could target P-gp and reduce its expression and the combination of paclitaxel and curcumin reversed the MDR of paclitaxel by targeting P-gp in cervical cancer cells (78).

\section{Breast cancer}

Anticancer activity. Breast cancer is the most common cancer in women worldwide (2). At present, paclitaxel is approved 
Table I. Effects of the combination of paclitaxel and curcumin on MDR reversal in various cancers.

\begin{tabular}{|c|c|c|c|c|c|c|c|}
\hline & $\begin{array}{c}\text { Cervical } \\
\text { cancer }\end{array}$ & $\begin{array}{l}\text { Breast } \\
\text { cancer }\end{array}$ & $\begin{array}{l}\text { Ovarian } \\
\text { cancer }\end{array}$ & $\begin{array}{l}\text { Brain } \\
\text { cancer }\end{array}$ & $\begin{array}{l}\text { Bladder } \\
\text { cancer }\end{array}$ & $\begin{array}{c}\text { Prostate } \\
\text { cancer }\end{array}$ & $\begin{array}{l}\text { Liver } \\
\text { cancer }\end{array}$ \\
\hline MAPKs & - & & & & & & \\
\hline $\mathrm{NF}-\kappa \mathrm{B}$ & - & - & - & - & - & & - \\
\hline Akt & - & - & - & - & & - & \\
\hline P-gp & - & - & & & & & \\
\hline MMP-9 & & & - & & & & \\
\hline TIMP-2 & & & + & & & & \\
\hline VEGF & & & & - & & & \\
\hline b-FGF & & & & - & & & \\
\hline hTERT & & & & - & & & \\
\hline $\operatorname{Lin} 28$ & & & & & & & - \\
\hline References & $(6,74-78)$ & $(83-86)$ & $(8,90-93)$ & $(95,96)$ & (98) & (103) & $(107,108)$ \\
\hline
\end{tabular}

and widely used for the treatment of breast cancer in clinic. Various studies have reported that the combination of paclitaxel and curcumin more effectively inhibited breast cancer cells than paclitaxel or curcumin alone due to their synergistic effect (79-87). Faião-Flores et al showed that the combination of paclitaxel and curcumin exhibited synergistic anticancer effect for the treatment of breast cancer cells by increasing the release of cytochrome $\mathrm{c}$ and activation of caspases, especially caspase-3 (79). Banerjee et al reported that curcumin significantly enhanced the apoptotic effect of paclitaxel in breast cancer MCF-7 cells via increasing the expression of p53 and p21 (80). Zhan et al showed that combination of paclitaxel and curcumin exhibited synergistic growth inhibition and significantly induced apoptosis via increasing Bcl-2 expression, but decreasing Bax expression in breast cancer MCF-7 cells. Furthermore, the combination of paclitaxel and curcumin potentiated antitumor efficacy of paclitaxel in the mouse models of breast cancer (81). Studies also showed that combining paclitaxel and curcumin with $\beta$-cyclodextrin triazine exhibited synergistic anticancer effect for the treatment of breast cancer $(82,83)$.

Effect on MDR reversal. MDR of paclitaxel significantly limits its therapeutic effect and clinical application. Royt et al demonstrated that the combination of paclitaxel and curcumin significantly improved the anticancer effect by reversing MDR of paclitaxel via inhibition of NF- $\mathrm{KB}(84)$. Inhibition of phosphorylation of IKBa contributed to the inhibition of $\mathrm{NF}-\kappa \mathrm{B}$ and paclitaxel induced the phosphorylation of IKBa to activate NF- $\kappa \mathrm{B}(85)$. However, curcumin inhibited the phosphorylation of IKBa to inhibit the activation of $\mathrm{NF}-\kappa \mathrm{B}(86)$. Paclitaxel activated the gene products of matrix metalloprotein-9 (MMP-9), COX-2, C-myc and cyclin D1, while curcumin inhibited their activation through inhibition of $\mathrm{NF}-\kappa \mathrm{B}$ and Akt $(85,86)$. Wang et al developed a multifunctional anti-cancer nanomedicine loaded with magnetic nanoparticles (MNPs), paclitaxel and curcumin and showed that the nanoparticles reduced the expression of $\mathrm{P}-\mathrm{gp}$ and increased paclitaxel accumulation in breast cancer MCF-7/ADR cells, thereby, enhancing the therapeutic efficacy of paclitaxel against breast cancer cells and the effect was due to reversing MDR of paclitaxel through inhibition of P-gp by curcumin (87).

\section{Ovarian cancer}

Anticancer activity. Ovarian cancer is one of the most common cancers in the female reproductive system and the fifth most common cause of cancer deaths in women worldwide; its incidence has been increasing recently (2). Paclitaxel has been used for the treatment of ovarian cancer for many years. Numerous studies have shown that the combination of paclitaxel and curcumin was more effective than paclitaxel alone for the treatment of ovarian cancer preclinically (82,88-93). The expression of potassium channel TREK-1 was increased in ovarian cancer cells and the inhibitors of potassium channels could inhibit the cell growth and proliferation of ovarian cancer cells. A study by Innamaa et al showed that curcumin inhibited ovarian cancer cell proliferation via inhibition of TREK-1 and enhanced the anticancer effect of paclitaxel against ovarian cancer (89). Deng et al reported that the combination of paclitaxel and curcumin blocked cell cycle arrest at G2/M and showed synergistic anticancer effect against human ovarian cancer cells HO-8910 (90).

Effect on MDR reversal. Paclitaxel is the substrate of $\mathrm{P}-\mathrm{gp}$ and cytochrome P450 3A2 (CYP3A2). Ganta et al reported that curcumin inhibited the expression of P-gp and CYP3A2 to enhance the bioavailability of paclitaxel and sensitized human ovarian cancer cells expressed P-gp and CYP3A2 to paclitaxel treatment (88). The transferrin (TF) receptor is increased in ovarian tumor cells because iron is necessary for DNA synthesis of the cells (91). Therefore, TF-targeted mixed 
micelles with paclitaxel and curcumin increased the inhibitory effect on ovarian cancer cells and reversed MDR of paclitaxel via inhibition of NF-kB and Akt $(92,93)$. MMP-9 is involved in cancer cell proliferation and metastasis by promoting tumor angiogenesis and is inhibited by tissue inhibitors of metalloproteinase-2 (TIMP-2). Deng et al reported that paclitaxel increased the expression of MMP-9 and reduced the expression of TIMP-2, leading to MDR. However, curcumin reduced the expression of MMP-9 and increased the expression of TIMP-2. Therefore, the combination of paclitaxel and curcumin can inhibit the growth of ovarian cancer cells by reversing MDR of paclitaxel (90).

\section{Brain cancer}

Anticancer activity. Brain cancer is the leading cause of death for children under the age of 19 (2). Glioblastoma is the deadliest brain tumor and highly resistant to anticancer drugs (94). Investigations have proved that the combination of paclitaxel and curcumin induced apoptosis of cancer cells and inhibited tumor growth more effectively than paclitaxel alone in a dosedependent manner for the treatment of brain cancer $(95,96)$. Hossain et al demonstrated that the combination of paclitaxel and curcumin activated the expression of caspase- 3 and caspase- 8 to induce cell apoptosis in human brain cancer LN18 and U138MG cells by western blot analysis (95). Bcl-2 family proteins such as Bax and Bcl-2 are the regulators of apoptosis, Bax promotes apoptosis but $\mathrm{Bcl}-2$ inhibits apoptosis. In this paper, Hossain et al also reported that the combination of paclitaxel and curcumin significantly up-regulated the expression of Bax, while greatly downregulated the expression of Bcl-2 in human brain cancer cells (95). Therefore, the results indicate that the combination of paclitaxel and curcumin exhibited synergistic anticancer effect for the treatment of brain cancer. Cui et al developed magnetic nanoparticles with the combination of paclitaxel and curcumin, and found that the combination yielded synergistic effects with significant inhibition of brain cancer cell growth compared to the single drug via apoptosis induction and cell cycle arrest. Furthermore, the magnetic nanoparticles with the combination of paclitaxel and curcumin greatly increased the survival rate of mice in an orthotopic mouse model of glioma (97).

Effect on MDR reversal. MDR of paclitaxel is developed mainly due to the activation of NF- $\mathrm{KB}$ and Akt, which are the mediators of cell survival, proliferation and metastasis. The activation of matrix metalloprotein-2 (MMP-2), MMP-9, survivin, human telomerase reverse transcriptase (hTERT), vascular endothelial growth factor (VEGF), and basic fibroblast growth factor (b-FGF) also results in MDR of paclitaxel. MDR is a major problem for paclitaxel in the treatment of brain cancer. Curcumin could inhibit the expression levels of NF- $\mathrm{kB}$, Akt, MMP-2, MMP-9, survivin, hTERT, VEGF, and b-FGF, therefore, the combination of paclitaxel and curcumin could enhance the anticancer effect of paclitaxel for the treatment of brain cancer by reversing MDR of paclitaxel (95). A study by Manju $e t$ al also showed that the multifunctional magnetic nanoparticles (MNPs) loaded with paclitaxel and curcumin showed stronger anticancer effect than the combination of paclitaxel and curcumin freely by targeting and reducing P-gp for the treatment of brain cancer (96).

\section{Bladder cancer}

Anticancer activity. Bladder cancer is the most common cancer in the urinary system and the ninth most common cancer worldwide (72). The common chemotherapeutic drugs for the treatment of bladder cancer include cisplatin, carboplatin, gemcitabine, paclitaxel, docetaxel, doxorubicin, fluorouracil, methotrexate, vinblastine, ifosfamide, and pemetrexed. Kamat et al demonstrated that the combination of paclitaxel and curcumin blocked cell cycle arrest at $\mathrm{G} 2 / \mathrm{M}$ in human bladder cancer cells and showed synergistic therapeutic effect against bladder cancer (98).

Effect on MDR reversal. Kamat et al also reported that curcumin reversed MDR of paclitaxel by inhibiting NF- $\mathrm{KB}$ to greatly enhance the effects of paclitaxel on proliferation inhibition and apoptosis induction compared to paclitaxel alone in bladder cancer cells (98).

\section{Prostate cancer}

Anticancer activity. Prostate cancer is the most common cause of cancer and the second-most common cause of death from cancer among men worldwide $(2,72)$. Numerous studies have showed that the combination of paclitaxel and curcumin were more effective than paclitaxel alone against prostate cancer through various mechanisms (99-101). Proliferation cell nuclear antigen (PCNA) and MMP-2 are both involved in cell proliferation and invasion of prostate cancer cells. Zhao et al have showed that the combination of paclitaxel and curcumin significantly decreased the quantities and expression levels of PCNA and MMP-2 in prostate cancer cells compared to paclitaxel alone (99). Tumor cell immigration from one organ to another contributes to tumor metastasis. Paclitaxel or curcumin alone could reduce the immigration of cancer cells and the combination of paclitaxel and curcumin exhibited synergistic antimetastasis effect in prostate cancer via inhibition of cell immigration (100). The results from the studies of Huang et al indicated that the expression of Bcl-2 was inhibited and the expression of Bax was enhanced when prostate cancer cells were treated with the combination of paclitaxel and curcumin (101). The study by Thomas et al also showed that the combination of paclitaxel and curcumin could effectively inhibit the growth of prostate cancer cells by activating the expression levels of p 21 and 553 to influence cell apoptosis (102).

Effect on MDR reversal. Mathur et al reported that the combination of paclitaxel and curcumin reversed MDR of paclitaxel and enhanced anticancer activity by inhibiting PI3K/Akt in prostate cancer cells (103).

\section{Liver cancer}

Anticancer activity. Liver cancer is one of the most common cancers and the second (in the USA) or third (worldwide) most common cause of deaths from cancer $(2,73,104)$. China has the highest rates of incidence and mortality of liver cancer in the world (105). The chemotherapeutic drugs such as 5-fluorouracil, doxorubicin, and cisplatin have been used for the treatment of liver cancer for many years. However, the effects of treatment are unsatisfactory because of MDR and other factors, resulting in the average survival time of only 
between 6 and 20 months (106). In general, liver cancer cells are highly resistant to paclitaxel (106). However, the studies by Zhou et al showed that curcumin significantly enhanced the sensitivity of liver cancer Hep3B cells to paclitaxel and the combination of paclitaxel and curcumin may provide a superior therapeutic index for the treatment of liver cancer (107).

Effect on MDR reversal. Lin28 is an RNA-binding protein that inhibits the process of pre-let-7 miRNAs to reduce tumorigenesis (108). Zhou et al found that the expression of Lin28 was directly activated by $\mathrm{NF}-\kappa \mathrm{B}$ and associated with the resistance of paclitaxel to liver cancer cells (107). Curcumin could down-regulate the expression of Lin 28 and $N F-\kappa B$ activation induced by paclitaxel to enhance the sensitivity of liver cancer cells to paclitaxel. Therefore, the combination of paclitaxel and curcumin showed synergistic effects on cell growth inhibition and apoptotic induction against liver cancer cells by reversing MDR of paclitaxel.

\section{Lung cancer}

Anticancer activity. Lung cancer is the most common cancer and most common cause of death from cancer worldwide $(2,73)$. The mortality of lung cancer has declined and survival rate has increased in the United Kingdom and the United States (109). However, the incidence and mortality of lung cancer are still increase in the developing countries, therefore, substantial efforts are needed to decrease the mortality of lung cancer. The studies by Boztas et al, found that the combination of paclitaxel and curcumin synergistically improved paclitaxel induced apoptosis in lung cancer H1299 cells, and enhanced the cell growth inhibition for a low $\mathrm{IC}_{50}$ values for the combination compared to paclitaxel or curcumin alone (82). Therefore, the combination of paclitaxel and curcumin may be an excellent choice for the treatment of lung cancer due to the synergistic anticancer effect. Muthoosamy et al developed a drug delivery system loaded with paclitaxel and curcumin by functionalizing reduced graphene oxide with an amphiphilic polymer PF-127 via hydrophobic assembly. Cell proliferation assay showed highly potent synergistic effect with the combination to inhibit the cell growth of lung cancer cells A549 with $\mathrm{IC}_{50} \sim 13.24 \mu \mathrm{g} / \mathrm{ml}$ (110). The possible mechanism may be associated with increased reactive oxygen species, mitochondrial membrane potential depletion and cell apoptosis (110).

Effect on MDR reversal. Study by $\mathrm{Su}$ et al showed that several drugs could induce drug resistance with increased expression of the multidrug resistance-associated protein (MRP1) but paclitaxel reversed drug-induced drug resistance in small cell lung cancer cells (111). Since curcumin also could reverse MDR induced by paclitaxel and other chemotherapeutic drugs in various cancers, the combination of paclitaxel and curcumin may have synergistic effects in reversing MDR in lung cancer cells.

\section{Conclusion}

Paclitaxel has been widely used for the treatment of various cancers including cervical, breast, ovarian, brain, prostate, liver and lung cancers. However, MDR greatly limits the anticancer efficacy and clinical application of paclitaxel. As we discussed in this review that curcumin alone or in combination with chemotherapeutic drugs may alter the signaling pathways and molecular interactions which regulate MDR. Numerous cell and animal studies have showed that the combination of paclitaxel and curcumin exhibited synergistic anticancer effect and reverse MDR of paclitaxel in various cancers therapy. Therefore, it is speculated that the combination of paclitaxel and curcumin may be an ideal strategy in clinical practice for cancer treatment. However, owing to the low water solubility of curcumin and paclitaxel, the combination of paclitaxel and curcumin may not be suitable to be administered as an intravenous infusion. Moreover, the formulation suitable for parenteral administration of the original product Taxol has to contain additional surfactants such as Cremophor EL that may cause acute hypersensitivity reactions and peripheral neuropathy. Therefore, the dosage for easy dissolution and absorption is the most serious challenge in clinical practice.

The prospect of the combination of paclitaxel and curcumin in clinical application for cancer therapy appears to be promising but also challenging. Therefore, the feasibility and effectiveness of the combination should be further evaluated in clinical studies. To our knowledge, there is no report of the combination of paclitaxel and curcumin in clinical setting for cancer treatment from the literature up to date. However, paclitaxel has been widely used for the treatment of patients with different cancers. Clinical trials of curcumin alone or in combination with other anticancer drugs have been reported and the safety and tolerability of curcumin in patients have been wellestablished in clinical studies (112-116). Dhillon et al reported a phase II trial of curcumin in patients with advanced pancreatic cancer (112). The results showed that oral administration of $8 \mathrm{~g}$ curcumin to the patients daily is well tolerated and has biological activity in some patients with pancreatic cancer (112). The combination of curcumin and gemcitabine in patients with advanced pancreatic cancer has also been reported (113). In addition, a randomized control trial has been conducted for the combination of curcumin with standard care FOLFOX (oxaliplatin + fluorouracil + folinic acid) chemotherapy in patients with inoperable colorectal cancer (114). Noteworthy, there are studies on the combination of docetaxel (a taxane derivative with similar chemical structure of paclitaxel) and curcumin in patients with advanced and metastatic breast cancer or castration-resistant prostate cancer $(115,116)$. The results indicate that some improvements were observed for biological and clinical responses in most breast cancer patients and a high response rate, good tolerability and patient acceptance were achieved in prostate cancer patients. Furthermore, the low bioavailability of curcumin could be markedly improved via the use of structural analogues or special formulations such as highly bioavailable curcumin (Theracurmin) and/or liposomal curcumin $(117,118)$. In addition, paclitaxel and curcumin could be encapsulated in biodegradable nanoparticles to avoid acute hypersensitivity reactions and peripheral neuropathy from Cremophor EL.

\section{Acknowledgements}

This study was financially supported by the National Natural Science Foundation of China (81341124,81101678), Science and Technology Support Project of Sichuan Province (2017JQ0013), Sichuan Provincial Human Resource and Social 
Security Department (2016-183), the Joint Fund of Sichuan Province, Luzhou City and Southwest Medical University (14JC0134, 14ZC0026, 14ZC0066), the Joint Fund of Luzhou City and Southwest Medical University (2013LZLY-K80, 2015LZCYD-S09 (4/8).

\section{References}

1. Chen W, Zheng R, Baade PD, Zhang S, Zeng H, Bray F, Jemal A, Yu XQ and He J: Cancer statistics in China, 2015. CA Cancer J Clin 66: 115-132, 2016.

2. Siegel RL, Miller KD and Jemal A: Cancer statistics, 2016. CA Cancer J Clin 66: 7-30, 2016.

3. Szekeres T and Novotny L: New targets and drugs in cancer chemotherapy. Med Princ Pract 11: 117-125, 2002.

4. Wu ES, Oduyebo T, Cobb LP, Cholakian D, Kong X, Fader AN, Levinson KL, Tanner EJ III, Stone RL, Piotrowski A, et al: Lymphopenia and its association with survival in patients with locally advanced cervical cancer. Gynecol Oncol 140: 76-82, 2016.

5. Sideris S, Aoun F, Zanaty M, Martinez NC, Latifyan S, Awada A and Gil T: Efficacy of weekly paclitaxel treatment as a single agent chemotherapy following first-line cisplatin treatment in urothelial bladder cancer. Mol Clin Oncol 4: 1063-1067, 2016.

6. Dilruba S and Kalayda GV: Platinum-based drugs: Past, present and future. Cancer Chemother Pharmacol 77: 1103-1124, 2016.

7. Pan X, Zhang X, Sun H, Zhang J, Yan M and Zhang H: Autophagy inhibition promotes 5 -fluorouraci-induced apoptosis by stimulating ROS formation in human non-small cell lung cancer A549 cells. PLoS One 8: e56679, 2013.

8. Emadi A, Jones RJ and Brodsky RA: Cyclophosphamide and cancer: Golden anniversary. Nat Rev Clin Oncol 6: 638-647, 2009.

9. Vanhoefer U, Harstrick A, Achterrath W, Cao S, Seeber S and Rustum YM: Irinotecan in the treatment of colorectal cancer: Clinical overview. J Clin Oncol 19: 1501-1518, 2001.

10. Xu T, Qin L, Zhu Z, Wang X, Liu Y, Fan Y, Zhong S, Wang X, Zhang X, Xia L, et al: MicroRNA-31 functions as a tumor suppressor and increases sensitivity to mitomycin-C in urothelial bladder cancer by targeting integrin $\alpha 5$. Oncotarget 7: 2744527457, 2016.

11. Bae YJ, Yoon YI, Yoon TJ and Lee HJ: Ultrasound-guided delivery of siRNA and a chemotherapeutic drug by using microbubble complexes: In vitro and in vivo evaluations in a prostate cancer model. Korean J Radiol 17: 497-508, 2016.

12. Zhou Q, Ye M, Lu Y, Zhang H, Chen Q, Huang S and Su S: Curcumin improves the tumoricidal effect of mitomycin $\mathrm{C}$ by suppressing ABCG2 expression in stem cell-like breast cancer cells. PLoS One 10: e0136694, 2015.

13. Wei Z, Liang L, Junsong L, Rui C, Shuai C, Guanglin Q, Shicai H, Zexing W, Jin W, Xiangming C, et al: The impact of insulin on chemotherapeutic sensitivity to 5-fluorouracil in gastric cancer cell lines SGC7901, MKN45 and MKN28. J Exp Clin Cancer Res 34: 64, 2015.

14. Talekar M, Ouyang Q, Goldberg MS and Amiji MM: Cosilencing of PKM-2 and MDR-1 sensitizes multidrug-resistant ovarian cancer cells to paclitaxel in a murine model of ovarian cancer. Mol Cancer Ther 14: 1521-1531, 2015.

15. Kenicer J, Spears M, Lyttle N, Taylor KJ,Liao L, Cunningham CA, Lambros M, MacKay A, Yao C, Reis-Filho J, et al: Molecular characterisation of isogenic taxane resistant cell lines identify novel drivers of drug resistance. BMC Cancer 14: 762-772, 2014.

16. Martín AJ, Alfonso PG, Rupérez AB and Jiménez MM: Nab-paclitaxel plus gemcitabine as first-line palliative chemotherapy in a patient with metastatic pancreatic cancer with Eastern Cooperative Oncology Group performance status of 2. Oncol Lett 12: 727-730, 2016.

17. Ebara S, Kobayashi Y, Sasaki K, Araki M, Sugimoto M, Wada K, Fujio K, Takamoto A, Watanabe T, Yanai H, et al: A case of metastatic urachal cancer including a neuroendocrine component treated with gemcitabine, cisplatin and paclitaxel combination chemotherapy. Acta Med Okayama 70: 223-227, 2016.

18. Kalaghchi B, Abdi R, Amouzegar-Hashemi F, Esmati E and Alikhasi A: Concurrent chemoradiation with weekly paclitaxel and cisplatin for locally advanced cervical cancer. Asian Pac J Cancer Prev 17: 287-291, 2016.
19. Yilmaz A, Alp E, Onen HI and Menevse S: Reduced BCL2 and CCND1 mRNA expression in human cervical cancer HeLa cells treated with a combination of everolimus and paclitaxel. Contemp Oncol (Pozn) 20: 28-32, 2016.

20. Trendowski M, Christen TD, Acquafondata C and Fondy TP: Effects of cytochalasin congeners, microtubule-directed agents, and doxorubicin alone or in combination against human ovarian carcinoma cell lines in vitro. BMC Cancer 15: 632-645, 2015.

21. van der Noll R, Marchetti S, Steeghs N, Beijnen JH, MerguiRoelvink MW, Harms E, Rehorst H, Sonke GS and Schellens JH: Long-term safety and anti-tumour activity of olaparib monotherapy after combination with carboplatin and paclitaxel in patients with advanced breast, ovarian or fallopian tube cancer. Br J Cancer 113: 396-402, 2015.

22. Huang L, Chen S, Yang W, Xu B, Huang T, Yang H, Zheng H, Wang Y, Song E, Zhang J, et al: Efficacy and safety analysis of trastuzumab and paclitaxel based regimen plus carboplatin or epirubicin as neoadjuvant therapy for clinical stage II-III, HER2-positive breast cancer patients: A phase 2, open-label, multicenter, randomized trial. Oncotarget 6: 18683-18692, 2015.

23. Xiao B, Si X, Han MK, Viennois E, Zhang M and Merlin D: Co-delivery of camptothecin and curcumin by cationic polymeric nanoparticles for synergistic colon cancer combination chemotherapy. J Mater Chem B Mater Biol Med 3: 7724-7733, 2015.

24. Tsuda N, Watari H and Ushijima K: Chemotherapy and molecular targeting therapy for recurrent cervical cancer. Chin J Cancer Res 28: 241-253, 2016.

25. Schwab CL, English DP, Roque DM and Santin AD: Taxanes: Their impact on gynecologic malignancy. Anticancer Drugs 25: 522-535, 2014.

26. Wani MC and Horwitz SB: Nature as a remarkable chemist: A personal story of the discovery and development of Taxol. Anticancer Drugs 25: 482-487, 2014.

27. Weaver BA: How Taxol/paclitaxel kills cancer cells. Mol Biol Cell 25: 2677-2681, 2014.

28. Zhang D, Yang R, Wang S and Dong Z: Paclitaxel: New uses for an old drug. Drug Des Devel Ther 8: 279-284, 2014.

29. Takashima S, Kiyoto S, Takahashi M, Hara F, Aogi K, Ohsumi S, Mukai R and Fujita Y: Clinical experience with nanoparticle albumin-bound paclitaxel, a novel taxane anticancer agent, and management of adverse events in females with breast cancer. Oncol Lett 9: 1822-1826, 2015.

30. Chen NC, Chyau CC, Lee YJ, Tseng HC and Chou FP: Promotion of mitotic catastrophe via activation of PTEN by paclitaxel with supplement of mulberry water extract in bladder cancer cells. Sci Rep 6: 20417, 2016.

31. Zhong ZF, Tan W, Wang SP, Qiang WA and Wang YT: Antiproliferative activity and cell cycle arrest induced by evodiamine on paclitaxel-sensitive and -resistant human ovarian cancer cells. Sci Rep 5: 16415, 2015.

32. Liu K, Cang S, Ma Y and Chiao JW: Synergistic effect of paclitaxel and epigenetic agent phenethyl isothiocyanate on growth inhibition, cell cycle arrest and apoptosis in breast cancer cells. Cancer Cell Int 13: 10, 2013.

33. Takatori E, Shoji T, Kumagai S, Sawai T, Kurose A and Sugiyama T: Are platinum agents, paclitaxel and irinotecan effective for clear cell carcinoma of the ovary? DNA damage detected with $\gamma \mathrm{H} 2 \mathrm{AX}$ induced by anticancer agents. J Ovarian Res 5: 16, 2012.

34. Harisa GI, Ibrahim MF, Alanazi F and Shazly GA: Engineering erythrocytes as a novel carrier for the targeted delivery of the anticancer drug paclitaxel. Saudi Pharm J 22: 223-230, 2014.

35. Wu ZH, Lu MK, Hu LY and Li X: Praziquantel synergistically enhances paclitaxel efficacy to inhibit cancer cell growth. PLoS One 7: e51721, 2012.

36. Li CM, Lu Y, Chen J, Costello TA, Narayanan R, Dalton MN, Snyder LM, Ahn S, Li W, Miller DD, et al: Orally bioavailable tubulin antagonists for paclitaxel-refractory cancer. Pharm Res 29: 3053-3063, 2012.

37. Oostendorp RL, Buckle T, Lambert G, Garrigue JS, Beijnen JH, Schellens JH and van Tellingen O: Paclitaxel in self-micro emulsifying formulations: Oral bioavailability study in mice. Invest New Drugs 29: 768-776, 2010.

38. Borst P and Schinkel AH: P-glycoprotein ABCB1: A major player in drug handling by mammals. J Clin Invest 123: 4131-4133, 2013.

39. Sui H, Fan ZZ and Li Q: Signal transduction pathways and transcriptional mechanisms of ABCB1/Pgp-mediated multiple drug resistance in human cancer cells. J Int Med Res 40: 426-435, 2012.

40. Kim H, Park GS, Lee JE and Kim JH: A leukotriene B4 receptor-2 is associated with paclitaxel resistance in MCF-7/DOX breast cancer cells. Br J Cancer 109: 351-359, 2013. 
41. Ran X, Yang J, Liu C, Zhou P, Xiao L and Zhang K: MiR-218 inhibits HMGB1-mediated autophagy in endometrial carcinoma cells during chemotherapy. Int J Clin Exp Pathol 8: 6617-6626, 2015.

42. Yang X, Iyer AK, Singh A, Choy E, Hornicek FJ, Amiji MM and Duan Z: MDR1 siRNA loaded hyaluronic acid-based CD44 targeted nanoparticle systems circumvent paclitaxel resistance in ovarian cancer. Sci Rep 5: 8509, 2015.

43. Yang X, Iyer AK, Singh A, Milane L, Choy E, Hornicek FJ, Amiji MM and Duan Z: Cluster of differentiation 44 targeted hyaluronic acid based nanoparticles for MDR1 siRNA delivery to overcome drug resistance in ovarian cancer. Pharm Res 32: 2097-2109, 2015

44. Mao K, Liu F, Liu X, Khuri FR, Marcus AI, Li M and Zhou W: Re-expression of LKB1 in LKB1-mutant EKVX cells leads to resistance to paclitaxel through the up-regulation of MDR1 expression. Lung Cancer 88: 131-138, 2015.

45. Chen SY, Hu SS, Dong Q, Cai JX, Zhang WP, Sun JY, Wang TT, Xie J, He HR, Xing JF, et al: Establishment of paclitaxel-resistant breast cancer cell line and nude mice models, and underlying multidrug resistance mechanisms in vitro and in vivo. Asian Pac J Cancer Prev 14: 6135-6140, 2013.

46. Januchowski R, Wojtowicz K, Sujka-Kordowska P, Andrzejewska M and Zabel M: MDR gene expression analysis of six drug-resistant ovarian cancer cell lines. BioMed Res Int 2013: 241763, 2013.

47. Wu G, Qin XQ, Guo JJ, Li TY and Chen JH: AKT/ERK activation is associated with gastric cancer cell resistance to paclitaxel. Int J Clin Exp Pathol 7: 1449-1458, 2014.

48. Jeong JY, Kim KS, Moon JS, Song JA, Choi SH, Kim KI, Kim TH and An HJ: Targeted inhibition of phosphatidyl inositol3-kinase $\mathrm{p} 10 \beta$, but not $\mathrm{p} 110 \alpha$, enhances apoptosis and sensitivity to paclitaxel in chemoresistant ovarian cancers. Apoptosis 18 : 509-520, 2013

49. Liu Z, Zhu G, Getzenberg RH and Veltri RW: The upregulation of PI3K/Akt and MAP kinase pathways is associated with resistance of microtubule-targeting drugs in prostate cancer. J Cell Biochem 116: 1341-1349, 2015.

50. Mei M, Xie D, Zhang Y, Jin J, You F, Li Y, Dai J and Chen X A new $2 \alpha, 5 \alpha, 10 \beta, 14 \beta$-tetraacetoxy-4(20),11-taxadiene (SIA) derivative overcomes paclitaxel resistance by inhibiting MAPK signaling and increasing paclitaxel accumulation in breast cancer cells. PLoS One 9: e104317, 2014.

51. Zhou M, Fan C and Tian N: Effects of curcumin on the gene expression profile of L-02 cells. Biomed Rep 3: 519-526, 2015.

52. Zhang Y, Liang D, Dong L, Ge X, Xu F, Chen W, Dai Y, $\mathrm{Li} \mathrm{H}$, Zou P, Yang S, et al: Anti-inflammatory effects of novel curcumin analogs in experimental acute lung injury. Respir Res 16: 43, 2015

53. Fan Z, Yao J, Li Y, Hu X, Shao H and Tian X: Anti-inflammatory and antioxidant effects of curcumin on acute lung injury in a rodent model of intestinal ischemia reperfusion by inhibiting the pathway of NF- $\kappa$ B. Int J Clin Exp Pathol 8: 3451-3459, 2015.

54. Ferreira VH, Nazli A, Dizzell SE, Mueller K and Kaushic C: The anti-inflammatory activity of curcumin protects the genital mucosal epithelial barrier from disruption and blocks replication of HIV-1 and HSV-2. PLoS One 10: e0124903, 2015.

55. Robles-Escajeda E, Das U, Ortega NM, Parra K, Francia G, Dimmock JR, Varela-Ramirez A and Aguilera RJ: A novel curcumin-like dienone induces apoptosis in triple-negative breast cancer cells. Cell Oncol (Dordr) 39: 265-277, 2016.

56. Park W, Amin AR, Chen ZG and Shin DM: New perspectives of curcumin in cancer prevention. Cancer Prev Res (Phila) 6 : 387-400, 2013

57. Zhou H, Beevers CS and Huang S: The targets of curcumin. Curr Drug Targets 12: 332-347, 2011.

58. Philip M, Rowley DA and Schreiber H: Inflammation as a tumor promoter in cancer induction. Semin Cancer Biol 14: 433-439, 2004

59. Cao F, Liu T, Xu Y, Xu D and Feng S: Curcumin inhibits cell proliferation and promotes apoptosis in human osteoclastoma cell through MMP-9, NF- $\mathrm{KB}$ and JNK signaling pathways. Int J Clin Exp Pathol 8: 6037-6045, 2015.

60. Bansal SS, Goel M, Aqil F, Vadhanam MV and Gupta RC: Advanced drug delivery systems of curcumin for cancer chemoprevention. Cancer Prev Res (Phila) 4: 1158-1171, 2011.

61. Guan F, Ding Y, Zhang Y, Zhou Y, Li M and Wang C: Curcumin suppresses proliferation and migration of MDA-MB-231 breast cancer cells through autophagy-dependent Akt degradation. PLoS One 11: e0146553, 2016.
62. Collett GP and Campbell FC: Curcumin induces c-jun N-terminal kinase-dependent apoptosis in HCT116 human colon cancer cells. Carcinogenesis 25: 2183-2189, 2004

63. Li X, Lu Y, Jin Y, Son JK, Lee SH and Chang HW: Curcumin inhibits the activation of immunoglobulin e-mediated mast cells and passive systemic anaphylaxis in mice by reducing serum eicosanoid and histamine levels. Biomol Ther (Seoul) 22: 27-34, 2014.

64. Liu D and Chen Z: The effect of curcumin on breast cancer cells. J Breast Cancer 16: 133-137, 2013.

65. Astuti P, D Utami E, Nugrahani AW and Sudjadi S: Genistein abrogates G2 arrest induced by curcumin in p53 deficient T47D cells. Daru 20: 82, 2012

66. Cheng C, Jiao JT, Qian Y, Guo XY, Huang J, Dai MC, Zhang L, Ding XP, Zong D and Shao JF: Curcumin induces G2/M arrest and triggers apoptosis via FoxO1 signaling in U87 human glioma cells. Mol Med Rep 13: 3763-3770, 2016.

67. Eom DW, Lee JH, Kim YJ, Hwang GS, Kim SN, Kwak JH, Cheon GJ, Kim KH, Jang HJ, Ham J, et al: Synergistic effect of curcumin on epigallocatechin gallate-induced anticancer action in PC3 prostate cancer cells. BMB Rep 48: 461-466, 2015.

68. Xiao J, Chu Y, Hu K, Wan J, Huang Y, Jiang C, Liang G and Li X: Synthesis and biological analysis of a new curcumin analogue for enhanced anti-tumor activity in HepG 2 cells. Oncol Rep 23: $1435-1441,2010$

69. Zhang Y, Jiang X, Peng K, Chen C, Fu L, Wang Z, Feng J, Liu Z, Zhang H, Liang G, et al: Discovery and evaluation of novel antiinflammatory derivatives of natural bioactive curcumin. Drug Des Devel Ther 8: 2161-2171, 2014.

70. Zhang Y, Zhao C, He W, Wang Z, Fang Q, Xiao B, Liu Z, Liang $\mathrm{G}$ and Yang S: Discovery and evaluation of asymmetrical monocarbonyl analogs of curcumin as anti-inflammatory agents. Drug Des Devel Ther 8: 373-382, 2014.

71. Olivera A, Moore TW, Hu F, Brown AP, Sun A, Liotta DC, Snyder JP, Yoon Y, Shim H, Marcus AI, et al: Inhibition of the $\mathrm{NF}-\kappa \mathrm{B}$ signaling pathway by the curcumin analog, 3,5-Bis(2pyridinylmethylidene)-4-piperidone (EF31): Anti-inflammatory and anti-cancer properties. Int Immunopharmacol 12: 368-377, 2012.

72. Torre LA, Bray F, Siegel RL, Ferlay J, Lortet-Tieulent J and Jemal A: Global cancer statistics, 2012. CA Cancer J Clin 65: 87-108, 2015

73. Balanda M, Quiero A, Vergara N, Espinoza G, Martín HS, Rojas G and Ramírez E: Prevalence of human papillomavirus infection among women presenting for cervical cancer screening in Chile, 2014-2015. Med Microbiol Immunol (Berl) 205: 585-594, 2016

74. Bava SV, Puliappadamba VT, Deepti A, Nair A, Karunagaran D and Anto RJ: Sensitization of taxol-induced apoptosis by curcumin involves down-regulation of nuclear factor-kappaB and the serine/threonine kinase Akt and is independent of tubulin polymerization. J Biol Chem 280: 6301-6308, 2005.

75. Bava SV, Sreekanth CN, Thulasidasan AKT, Anto NP, Cheriyan VT, Puliyappadamba VT, Menon SG, Ravichandran SD and Anto RJ: Akt is upstream and MAPKs are downstream of $\mathrm{NF}-\kappa \mathrm{B}$ in paclitaxel-induced survival signaling events, which are down-regulated by curcumin contributing to their synergism. Int J Biochem Cell Biol 43: 331-341, 2011.

76. Sreekanth CN, Bava SV, Sreekumar E and Anto RJ: Molecular evidences for the chemosensitizing efficacy of liposomal curcumin in paclitaxel chemotherapy in mouse models of cervical cancer. Oncogene 30: 3139-3152, 2011.

77. Dang YP, Yuan XY, Tian R, Li DG and Liu W: Curcumin improves the paclitaxel-induced apoptosis of HPV-positive human cervical cancer cells via the NF- $\kappa \mathrm{B}-\mathrm{p} 53$-caspase-3 pathway. Exp Ther Med 9: 1470-1476, 2015.

78. Punfa W, Suzuki S, Pitchakarn P, Yodkeeree S, Naiki T, Takahashi S and Limtrakul P: Curcumin-loaded PLGA nanoparticles conjugated with anti- P-glycoprotein antibody to overcome multidrug resistance. Asian Pac J Cancer Prev 15: 9249-9258, 2014.

79. Faião-Flores F, Suarez JAQ, Pardi PC and Maria DA: DM-1, sodium 4-(5-(4-hydroxy-3-methoxyphenyl)-3-oxo-penta-1,4dienyl)-2-methoxy-phenolate: A curcumin analog with a synergic effect in combination with paclitaxel in breast cancer treatment. Tumour Biol 33: 775-785, 2012.

80. Banerjee M, Singh P and Panda D: Curcumin suppresses the dynamic instability of microtubules, activates the mitotic checkpoint and induces apoptosis in MCF-7 cells. FEBS J 277: 3437-3448, 2010 
81. Zhan Y, Chen Y, Liu R, Zhang H and Zhang Y: Potentiation of paclitaxel activity by curcumin in human breast cancer cell by modulating apoptosis and inhibiting EGFR signaling. Arch Pharm Res 37: 1086-1095, 2014.

82. Boztas AO, Karakuzu O, Galante G, Ugur Z, Kocabas F, Altuntas CZ and Yazaydin AO: Synergistic interaction of paclitaxel and curcumin with cyclodextrin polymer complexation in human cancer cells. Mol Pharm 10: 2676-2683, 2013.

83. Thadakapally R, Aafreen A, Aukunuru J, Habibuddin M and Jogala S: Preparation and characterization of PEG-albumincurcumin nanoparticles intended to treat breast cancer. Indian $\mathbf{J}$ Pharm Sci 78: 65-72, 2016.

84. Royt M, Mukherjee S, Sarkar R and Biswas J: Curcumin sensitizes chemotherapeutic drugs via modulation of PKC telomerase, NF-kappaB and HDAC in breast cancer. Ther Deliv 2: 1275-1293, 2011.

85. Aggarwal BB, Shishodia S, Takada Y, Banerjee S, Newman RA, Bueso-Ramos CE and Price JE: Curcumin suppresses the paclitaxel-induced nuclear factor-kappaB pathway in breast cancer cells and inhibits lung metastasis of human breast cancer in nude mice. Clin Cancer Res 11: 7490-7498, 2005.

86. Kang HJ, Lee SH, Price JE and Kim LS: Curcumin suppresses the paclitaxel-induced nuclear factor-kappaB in breast cancer cells and potentiates the growth inhibitory effect of paclitaxel in a breast cancer nude mice model. Breast J 15: 223-229, 2009.

87. Wang J, Wang F, Li F, Zhang W, Shen Y, Zhou D and Guo S: A multifunctional poly(curcumin) nanomedicine for dual-modal targeted delivery, intracellular responsive release, dual-drug treatment and imaging of multidrug resistant cancer cells. J Mater Chem B Mater Biol Med 4: 2954-2962, 2016.

88. Ganta S, Devalapally H and Amiji M: Curcumin enhances oral bioavailability and anti-tumor therapeutic efficacy of paclitaxel upon administration in nanoemulsion formulation. J Pharm Sci 99: 4630-4641, 2010.

89. Innamaa A, Jackson L, Asher V, van Schalkwyk G, Warren A, Keightley A, Hay D, Bali A, Sowter H and Khan R: Expression and effects of modulation of the $\mathrm{K} 2 \mathrm{P}$ potassium channels TREK-1 (KCNK2) and TREK-2 (KCNK10) in the normal human ovary and epithelial ovarian cancer. Clin Transl Oncol 15: 910-918, 2013.

90. Deng S, Xu J, Li R and Zhou Q: Inhibitory effect of curcuminloaded solid lipid nanoparticles combined with paclitaxel on human ovarian cancer cell line HO-8910. China Pharmacy 24: 1756-1759, 2013. http://en.cnki.com.cn/Article_en/ CJFDTOTAL-ZGYA201319013.htm.

91. Abouzeid AH, Patel NR, Sarisozen C and Torchilin VP: Transferrin-targeted polymeric micelles co-loaded with curcumin and paclitaxel: Efficient killing of paclitaxel-resistant cancer cells. Pharm Res 31: 1938-1945, 2014.

92. Liu Z, Zhu YY, Li ZY and Ning SQ: Evaluation of the efficacy of paclitaxel with curcumin combination in ovarian cancer cells. Oncol Lett 12: 3944-3948, 2016.

93. Kar R, Sharma C, Sen S, Jain SK, Gupta SD and Singh N: Response of primary culture of human ovarian cancer cells to chemotherapy: In vitro individualized therapy. J Cancer Res Ther 12: 1050-1055, 2016.

94. Galia A, Calogero AE, Condorelli R, Fraggetta F, La Corte A, Ridolfo F, Bosco P, Castiglione R and Salemi M: PARP-1 protein expression in glioblastoma multiforme. Eur J Histochem 56: e9, 2012.

95. Hossain M, Banik NL and Ray SK: Synergistic anti-cancer mechanisms of curcumin and paclitaxel for growth inhibition of human brain tumor stem cells and LN18 and U138MG cells. Neurochem Int 61: 1102-1113, 2012.

96. Manju S, Sharma CP and Sreenivasan K: Targeted coadministration of sparingly soluble paclitaxel and curcumin into cancer cells by surface engineered magnetic nanoparticles. J Mater Chem 21: 15708-15717, 2011.

97. Cui Y,Zhang M,Zeng F, Jin H, Xu Q and Huang Y: Dual-targeting magnetic PLGA Nanoparticles for codelivery of paclitaxel and curcumin for brain tumor therapy. ACS Appl Mater Interfaces 8: 32159-32169, 2016.

98. Kamat AM, Sethi G and Aggarwal BB: Curcumin potentiates the apoptotic effects of chemotherapeutic agents and cytokines through down-regulation of nuclear factor-kappaB and nuclear factor-kappaB-regulated gene products in IFN-alpha-sensitive and IFN-alpha-resistant human bladder cancer cells. Mol Cancer Ther 6: 1022-1030, 2007.
99.Zhao H, Yu X, Qi R, Shang F and Su Z: Inhibitory effects of curcumin in combination with paclitaxel on prostate cancer xenografted model. Xiandai Shengwu Yixue Jinzhan 10: 823-827, 2010. (In Chinese)

100. Wand D, Qi R, Zhao H and Yu X: Effects of curcumin combined with paclitaxel on the invasion and senescence of human prostatic carcinoma PC3 cells. Xiandai Shengwu Yixue Jinzhan 12: 6239-6241, 2012. (In Chinese)

101. Huang YT, Huang DM, Chueh SC, Teng CM and Guh JH: Alisol $\mathrm{B}$ acetate, a triterpene from Alismatis rhizoma, induces Bax nuclear translocation and apoptosis in human hormone-resistant prostate cancer PC-3 cells. Cancer Lett 231: 270-278, 2006.

102. Thomas SL, Zhong D, Zhou W, Malik S, Liotta D, Snyder JP, Hamel E and Giannakakou P: EF24, a novel curcumin analog, disrupts the microtubule cytoskeleton and inhibits HIF-1. Cell Cycle 7: 2409-2417, 2008.

103. Mathur A, Abd Elmageed ZY, Liu X, Kostochka ML, Zhang H, Abdel-Mageed AB and Mondal D: Subverting ER-stress towards apoptosis by nelfinavir and curcumin coexposure augments docetaxel efficacy in castration resistant prostate cancer cells. PLoS One 9: e103109, 2014.

104. Yang JD and Roberts LR: Hepatocellular carcinoma: A global view. Nat Rev Gastroenterol Hepatol 7: 448-458, 2010.

105. Wei KR, Yu X, Zheng RS, Peng XB, Zhang SW, Ji MF, Liang ZH, Ou ZX and Chen WQ: Incidence and mortality of liver cancer in China, 2010. Chin J Cancer 33: 388-394, 2014.

106. Byam J, Renz J and Millis JM: Liver transplantation for hepatocellular carcinoma. Hepatobiliary Surg Nutr 2: 22-30, 2013.

107.Zhou M, Li Z, Han Z and Tian N: Paclitaxel-sensitization enhanced by curcumin involves down-regulation of nuclear factor- $\kappa$ B and Lin28 in Hep3B cells. J Recept Signal Transduct Res 35: 618-625, 2015.

108. O'Day E, Le MTN, Imai S, Tan SM, Kirchner R, Arthanari H, Hofmann O, Wagner G and Lieberman J: An RNA-binding protein, Lin28, recognizes and remodels g-quartets in the microRNAs (miRNAs) and mRNAs it regulates. J Biol Chem 290: 17909-17922, 2015.

109. Dubey AK, Gupta U and Jain S: Epidemiology of lung cancer and approaches for its prediction: A systematic review and analysis. Chin J Cancer 35: 71-83, 2016.

110. Muthoosamy K, Abubakar IB, Bai RG, Loh HS and Manickam S: Exceedingly higher co-loading of curcumin and paclitaxel onto polymer-functionalized reduced graphene oxide for highly potent synergistic anticancer treatment. Sci Rep 6: 32808, 2016.

111. Su GM, Davey MW and Davey RA: Induction of broad drug resistance in small cell lung cancer cells and its reversal by paclitaxel. Int J Cancer 76: 702-708, 1998.

112. Dhillon N, Aggarwal BB, Newman RA, Wolff RA, Kunnumakkara AB, Abbruzzese JL, Ng CS, Badmaev V and Kurzrock R: Phase II trial of curcumin in patients with advanced pancreatic cancer. Clin Cancer Res 14: 4491-4499, 2008.

113. Epelbaum R, Schaffer M, Vizel B, Badmaev V and Bar-Sela G: Curcumin and gemcitabine in patients with advanced pancreatic cancer. Nutr Cancer 62: 1137-1141, 2010.

114. Irving GR, Iwuji CO, Morgan B, Berry DP, Steward WP, Thomas A, Brown K and Howells LM: Combining curcumin (C3-complex, Sabinsa) with standard care FOLFOX chemotherapy in patients with inoperable colorectal cancer (CUFOX): Study protocol for a randomised control trial. Trials 16: 110, 2015.

115. Bayet-Robert M, Kwiatkowski F, Leheurteur M, Gachon F, Planchat E, Abrial C, Mouret-Reynier MA, Durando X, Barthomeuf $\mathrm{C}$ and Chollet P: Phase I dose escalation trial of docetaxel plus curcumin in patients with advanced and metastatic breast cancer. Cancer Biol Ther 9: 8-14, 2010.

116. Mahammedi H, Planchat E, Pouget M, Durando X, Curé H, Guy L, Van-Praagh I, Savareux L, Atger M, Bayet-Robert M, et al: The new combination docetaxel, prednisone and curcumin in patients with castration-resistant prostate cancer: A pilot phase II study. Oncology 90: 69-78, 2016.

117. Kanai M, Otsuka Y, Otsuka K, Sato M, Nishimura T, Mori Y, Kawaguchi M, Hatano E, Kodama Y, Matsumoto S, et al: A phase I study investigating the safety and pharmacokinetics of highly bioavailable curcumin (Theracurmin) in cancer patients. Cancer Chemother Pharmacol 71: 1521-1530, 2013.

118. Storka A, Vcelar B, Klickovic U, Gouya G, Weisshaar S, Aschauer S, Bolger G, Helson L and Wolzt M: Safety, tolerability and pharmacokinetics of liposomal curcumin in healthy humans. Int J Clin Pharmacol Ther 53: 54-65, 2015. 